\title{
Hepatic alveolar echinococcosis
}

Olivier Detry ${ }^{\mathrm{a}, \mathrm{b}}$, Nicolas Meurisse ${ }^{\mathrm{a}, \mathrm{b}}$, Jean Delwaide ${ }^{\mathrm{b}, \mathrm{c}}$, Jean-Baptiste Giot ${ }^{\mathrm{b}, \mathrm{d}}$, Philippe Leonard ${ }^{\mathrm{b}, \mathrm{d}}$, Bertrand Losson $^{\mathrm{b}, \mathrm{e}}$, Marie-Pierre Hayette ${ }^{\mathrm{b}, \mathrm{f}}$, Noella Bletard ${ }^{\mathrm{b}, \mathrm{g}}$, Paul Meunier $^{\mathrm{b}, \mathrm{h}}$ and Pierre Honoré $\mathrm{a}^{\mathrm{a}, \mathrm{b}}$

${ }^{a}$ Department of Abdominal Surgery and Transplantation, CHU Liege, University of Liege (CHU-ULg), Liege, Belgium;

${ }^{\mathrm{b}}$ Multidisciplinary Unit for Echinococcosis Management and Research of the University of Liege (Echino-Liege), University of Liege, Liege, Belgium; 'Department of Hepatogastroenterology, CHU Liege, University of Liege (CHU-ULg), Liege, Belgium; ${ }^{\text {d Department }}$ of Infectious diseases, CHU Liege, University of Liege (CHU-ULg), Liege, Belgium; 'Laboratory of Parasitology and Pathology of Parasitic Diseases, Faculty of Veterinary Medicine, University of Liege (ULg), Liege, Belgium; fDepartment of Microbiology, CHU Liege, University of Liege (CHU-ULg), Liege, Belgium; ${ }^{9}$ Department of Pathology, CHU Liege, University of Liege (CHU-ULg), Liege, Belgium; ${ }^{\text {h}}$ Department of Radiology, CHU Liege, University of Liege (CHU-ULg), Liege, Belgium

A 79-year old female patient with past history of breast adenocarcinoma underwent an abdominal computed tomography (CT) for asthenia and nausea. This CT demonstrated three separate hepatic lesions that were in large part necrotic, with peripheral calcifications and slow heterogeneous contrast uptake (Figure 1). Diagnosis of hepatic alveolar echinococcosis (AE) was made based on $C T$ imaging and positive serology for Echinococcocus multilocaris. The patient was treated with albendazole $800 \mathrm{mg}$ per day for two months before undergoing hepatic surgery allowing radical resection of all lesions. Macroscopically, the resected tissue showed white masses (Figure 2) with irregular multilocular, necrotic and cystic cavities (Figure 3). Pathology confirmed the diagnosis of AE. The patient refused postoperative treatment with albendazole due to side effects. She was well one year later, without evidence of AE recurrence, and a progressive decrease of anti-echinococcosis antibody levels.

$A E$ is a severe parasitic zoonosis caused by E. Multilocularis cestode worms. AE is described in the northern hemisphere, and local cases have been described in Wallonia [1,2] where up to $50 \%$ of the red foxes are infected [3] and where dogs might also be infected [4]. More than 15 local cases were treated at the $\mathrm{CHU}$ Liege these last 15 years. Association of radical surgery and albendazole $(10 \mathrm{mg} / \mathrm{kg}$ in two daily doses) for two years is recommended in operable patients, and life-long albendazole is necessary in patients in whom radical surgical resection of all parasitic lesions is not

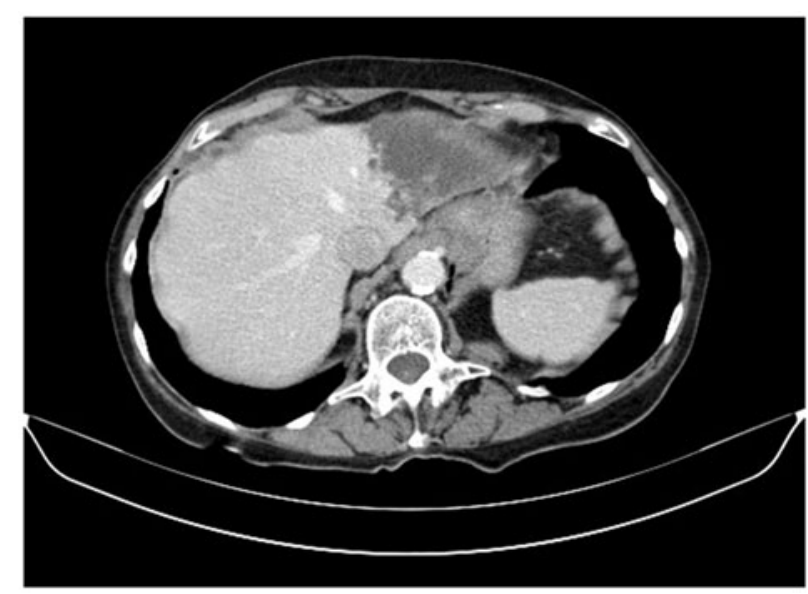

Figure 1. Computed tomography of the liver demonstrating the biggest lesion of alveolar echinococcosis invading the segments II and III.

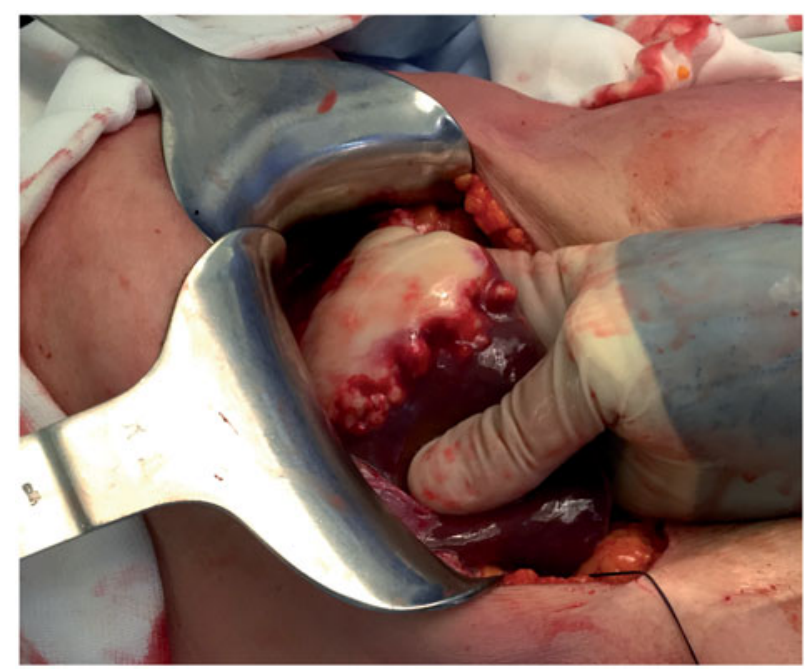

Figure 2. Operative picture demonstrating the alveolar echinococcosis as a white lesion at the surface of segment III.

CONTACT Olivier Detry oli.detry@chu.ulg.ac.be; olivier.detry@transplantation.be Department of Abdominal Surgery and Transplantation, CHU Liege, University of Liege (CHU-ULg), Liege, Belgium

(c) 2018 The Royal Belgian Society for Surgery 


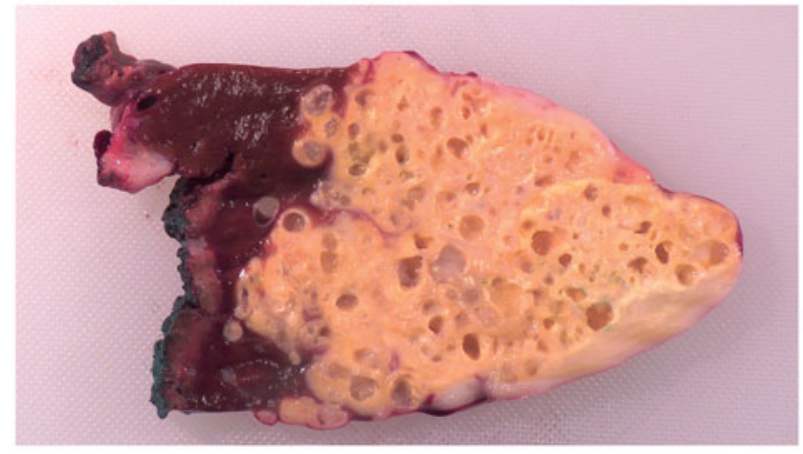

Figure 3. Section of the resected segment II and III.

possible $[5,6]$. Prevention consists of avoiding eating fresh vegetables or fruits that grow at less than $50 \mathrm{~cm}$ from the ground, and avoiding contact with wild foxes and dogs. Vegetable cooking (at least $10 \mathrm{~min}$ at $60^{\circ} \mathrm{C}, 5 \mathrm{~min}$ at $70^{\circ} \mathrm{C}$, or $1 \mathrm{~min}$ at $100^{\circ} \mathrm{C}$ ), but not freezing, is efficient to inactivate the eggs (oncospheres).

\section{Disclosure Statement}

No potential conflict of interest was reported by the authors.

\section{References}

[1] Delbecque K, Detry O, Hayette MP, et al. A case of hepatic alveolar echinococcosis contracted in Belgium. Acta Gastroenterol Belg. 2002;65: 55-60.

[2] Detry O, Honore C, Delwaide J, et al. Endemic alveolar echinococcosis in Southern Belgium? Acta Gastroenterol Belg. 2005;68:1-4.

[3] Losson B, Kervyn T, Detry J, et al. Prevalence of Echinococcus multilocularis in the red fox (Vulpes vulpes) in southern Belgium. Vet Parasitol. 2003; 117:23-28.

[4] Caron Y, Losson BJ, Bayrou C, et al. Cranial abdominal mass due to Echinococcus multilocularis in a two-year-old wirehaired Dachshund in Wallonia (Belgium). Vet Rec Case Rep. 2017;5: e000413.

[5] McManus DP, Zhang W, Li J, et al. Echinococcosis. Lancet. 2003;362:1295-1304.

[6] McManus DP, Gray DJ, Zhang W, et al. Diagnosis, treatment, and management of echinococcosis. BMJ. 2012;344:e3866. 